\title{
Effect of incorrect mix ratio on strength of two component adhesive Butt-Joints tested at eleva- ted temperature
}

\author{
Jakub Szabelski ${ }^{1,1}$ \\ ${ }^{1}$ Lublin University of Technology, Faculty of Mechanical Engineering, Nadbystrzycka 36, 20-618 \\ Lublin, Poland, j.szabelski@pollub.pl
}

\begin{abstract}
The aim of this study was to determine the impact of the incorrect mix ratio on the strength of joints bonded with a commercial epoxy adhesive compo-sition. The performance of cold-cured as well as accelerated cured butt joints was monitored at elevated temperature conditions. The obtained data was subjected to statistical analysis to show the correlation between joint strength at high temperature and incorrect mix ratio. The degradation of adhesive material properties with increase of hardener ratio in adhesive material was observed, as well as the change in failure type from mixed type to clearly cohesive (for inadequate volume of harde-ner) or adhesive (for excessive amount of hardener). Surprisingly insufficiency of hardener doesn't affect the strength of joint in such manner. General recommend-dation were drawn for the preparation of two-component epoxy adhesives for joints to be used in elevated temperature, particularly when uncertainty regarding the correct resin/hardener mix ratio and future research was planned.
\end{abstract}

Keywords: adhesive joints, adhesive materials, tensile strength, testing, elevated temperature, incorrect mixing ratio,

\section{Introduction}

The availability of a wide range of adhesive compositions on the market requires of the engineers basic knowledge regarding the groups and characteristics of common products. The differences between adhesives concern their application technology, cure procedures and, last but not least, the strength properties of the adhesive joint, which is after all a crucial aspect determining the suitability of a given adhesive for the particular application. The classification of adhesives for structural applications proposed in [1] includes detailed groups of adhesives and subgroups classified according to cure mechanisms:

1) Adhesives cured by chemical reaction:
a) two-component adhesives,
b) one-component adhesives activated by catalyst or curing agent,
c) adhesives cured by moisture,
d) adhesives cured by UV light exposure,

\footnotetext{
${ }^{1}$ Corresponding author: j.szabelski@poiiub.pl

Reviewers: Miroslav Müller, Petr Valášek
} 
e) anaerobic adhesives catalysed by substrate,

f) adhesives in the form of tapes, films, granules, etc,

2) Adhesives cured by solvent evaporation:
a) contact adhesives,
b) adhesives cured by pressure,
c) reactive adhesives,
d) resin-based adhesives,

3) Adhesives cured on cooling (hot-melt adhesives).

However in practice, adhesives frequently escape the traditional classification by representing the characteristics of different groups. Epoxy adhesives, for that matter, may form compositions cured by: mixing the resin with the curing agent, or by exposing the onecomponent composition to heat treatment.

Adhesives that set as a result of a chemical reaction between their components upon mixing share one common feature: they are produced as multi-component products, which cure as a result of a chemical reaction between two or more separate components. It is of critical importance that the constituents of the adhesive mix must be dosed at the correct ratio. The "base material" and the curing agent usually differ in colour so as to facilitate the visual inspection of the correct dosage while mixing. The working life of the mixed composition must be observed, as beyond that time the adhesive cannot be successfully dispensed and bond the adherends. The suggested mix ratio is specified by the manufacturer in the form of fixed ratio or a ratio range, given by volume or by weight. Apparently, it is only by strict adherence to component mixing ratio and specified bonding conditions that we can obtain a quality joint that will exhibit optimal strength properties. However, certain findings, such as presented in the work [2] are contrary to the accepted state, proving that certain adhesives develop full shear strength at a different mix ratio than declared by the manufacturer or suggested by the stoichiometric analysis.

Chemo-setting adhesive mass with an insufficient content of hardening agent per resin unit will not become completely polymerised. On the other hand, excessive addition of hardener will produce a fragile and brittle adhesive composition. Furthermore, the excess of unprocessed hardening agent could result in corrosion of the metallic surfaces of adherends [3]. Other properties of adhesives, such as heat resistance or stiffness, may also become compromised by the incorrect resin/hardener mix ratio. The role of imbalance in the proportion of hardener in the adhesive mix should be further explored, with a view to benefiting adhesive joint strength properties.

With the majority of formerly conducted studies into determining the optimal resin/ hardener ratio focusing on experimental character, there have been few researches employing computational methods to resolve the issue. Although stoichiometric analyses could provide data regarding the molecular balance in the reaction (hence the correct concen-tration of reagents), nevertheless the obtained values rather serve as a reference point for the experimental analyses $[4,5]$. In the case of epoxy adhesives, a certain range of curing agents, apart from the traditional involvement in the polymerisation as a result of reactions between components, play an additional role and act as catalysts in the polymerisation among epoxy groups, thus reducing the participation of these groups in the reaction with the hardener. As a result, the actual amount of the hardening agent necessary for the reaction to occur is lower than it would seem based on the results from the stoichiometric analysis. For instance, the optimal amount of acid anhydride curing agents is estimated at $85-95 \%$ of the stoichiometric relationship [6].

Epoxy adhesives are cured by long-chain fatty acid polyamide, obtained in the reaction of dibasic organic acid, employed in polycondensation with surplus ethylenediamine or diethylenetriamine, as a result of which amides with free amine groups are produced. Thus obtained resin/hardener ratio does not need to be strictly observed, and its measuring may be 
carried out in the visual method, until reaching a roughly similar amounts to the recommendded ones $[7,8]$.

The main aim of the conducted research was the analysis of degradation of cylindrical butt adhesive joints resulting from the incorrect resin/hardener mix ratio, not in room- but in elevated temperature conditions. Examined adhesive joints were prepared both: cold-cured as well as accelerated cured at high temperature. The goal was to discover if lack of hardener is as unwanted as its excess or if one of this occurrences is more undesirable than the other. There has been significant research conducted on strength of adhesive joints regarding mix ratio of components $[9,10,11,12,13,14]$ however, none of these consider butt joints examined at elevated temperature and cured using various mechanisms.

\section{Materials}

Regarding the selection of the adhesive composition subjected to testing, it was resolved that, for the sake of its suitability for a range of various applications, the joints will be bonded with the versatile and multi-purpose Loctite Hysol 9492. The producer declares that it can be used in traditional bonding applications, as well as sealing and repair of various materials (e.g. to remove pores and surface irregularities from casts and forgings). The adhesive is available in a double-cartridge dispensing system with a static mixer nozzle, mixing the adhesive upon dispensing at a $2: 1 \mathrm{resin} /$ hardener mix ratio by volume, 100:50 mix ratio by weight. The adhesive mass is a white opaque paste, which working life once it is mixed is approx. $15 \mathrm{~min}$. The fixture time of the adhesive composition, i.e. the time it develops the shear strength of $0.1 \mathrm{MPa}$, is $75 \mathrm{~min}$. The selected adhesive is quite commonly used for research due to its heat resistance and non-conductivity properties as well as handy dispenser and above all good market accessibility $[15,16]$.

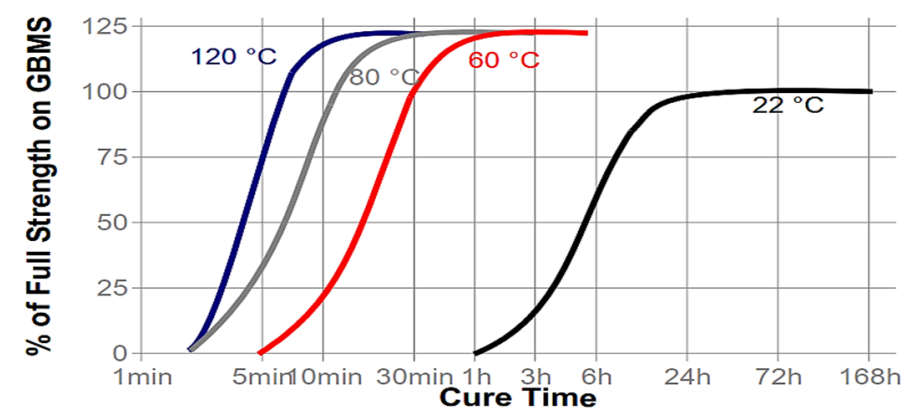

Fig. 1. Cure time and strength of joint depending on curing conditions [15]

Hysol 9492 develops complete cure within 3 days at room temperature, but elevated temperatures may be used to accelerate the cure. Elevated temperature cure allows obtaining $25 \%$ higher joint strength than cold-cure (Fig. 1) [15, 16].

\section{Research method}

The tests conducted to evaluate the axial-tensile strength of samples are fully compliant with the International Standard EN 15870:2009 (Adhesives - Determination of tensile strength of butt joints) [17]. The tests were performed on the test set-up based on the MTS Bionix Servohydraulic Test System. The set-up furthermore included the environmental chamber, for testing at elevated/reduced temperature in the range of temperatures from $40^{\circ} \mathrm{C}$ to $+250^{\circ} \mathrm{C}$. 


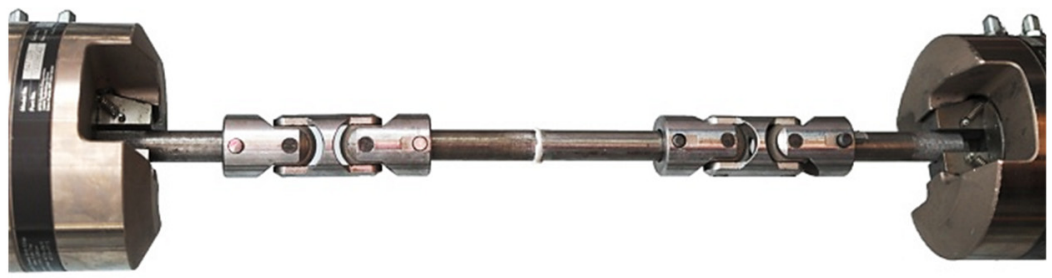

Fig. 2. Articulated grip of the testing machine

The samples were clamped with uniaxial self-centring hydraulic grips for cylindrical specimens (the specimen diameter range of $ø 14-20.8 \mathrm{~mm}$ ), with self-developed doublearticulated grips, compensating for axial errors of clamped specimens, which ensured axial tension loading of the test specimens (Fig. 2). The tests were controlled using dedicated software: MTS Test Works 4 SH.

The cylindrical test samples (diameter $d=20 \mathrm{~mm}$, length $\mathrm{L}=100 \mathrm{~mm}$ ) used in the experiments were made of S235JR steel drawn bar. The butting face of the samples was prepared for bonding according to the standard PN-EN 13887:2005 (Structural Adhesives Guidelines for surface preparation of metals and plastics prior to adhesive bonding) [18]. The ends of test samples were drilled through to create the holes for attaching the specimens in the articulated grip. The tests were carried out in 80 repetitions, i.e. 80 test sample series, whose butting faces were subjected to additional mechanical treatment upon joint failure, with a view to reusing the samples in another test series.

The required surface roughness of all samples for bonding $(\mathrm{Ra}=3.4 \pm 0.6 \mu \mathrm{m}$ - which represented an intermediate-quality finish) was achieved by turning. In order to minimise the impact of corrosion processes, the time between mechanical pre-treatment and bonding did not exceed $2 \mathrm{~h}$.

The proper coaxial positioning and alignment of adherends during bonding was reali-sed on a specially-built stand. The self-developed apparatus employed the fixed mass of the top adherend as the source of loading on the joint; thus exerted load amounted to $8 \mathrm{kPa}$.

Prior to bonding, the specimens were subjected to necessary pre-treatment operations of cleaning and degreasing by means of a degreasing and industrial cleaning agent, Loctite 7036. The adhesive mass was dispensed following careful measurement of resin and hardener by means of FAWAG TP2/1 precision balance, which offers accuracy of $0.1 \mathrm{~g}$. The total mass of the adhesive composition produced in a single measurement was 15-20 g. The adhesive components were mixed for $3 \mathrm{~min}$, after which time the obtained mass was subjected to vacuum degassing for additional $5 \mathrm{~min}$. The total time from the degreasing to application of the adhesive did not exceed 15 min (always within working time). The adherends were bonded with the amount of adhesive that guaranteed consistent bond, free from debonding on account of adhesive mass shortage. Upon assembly the adhesive surfaced on the sides of the specimens in the form of a minor flash, which was not in any way removed [17].

The complete process of sample preparation, involving adherend preparation, degreasing, preparing the adhesive mix, joint assembly and post-curing (if necessary) was compliant with the relevant norm, and did not exceed the total time of $4 \mathrm{~h}$. In each series, 4 sets of 9 samples of identical resin/hardener ratio were produced: 2 post-cured in the thermal hardening process, and 2 cured at room temperature [11]. This procedure minimised potential test result errors resulting from discrepancies in the adhesive preparation process. Samples to be postcured were placed in a cold electric heat chamber, controlled with a Shimaden FP93 digital controller. Post curing was conducted according to the plan of experiment (Table 1). The post curing time was controlled and registered until stabilisation of set temperature level. Both 
sample variants, post-cured and non-post-cured, were conditioned at constant $25^{\circ} \mathrm{C}$ and constant relative humidity of $50 \%$.

Table 1. Adhesive butt joint strength testing plan

\begin{tabular}{|c|c|c|}
\hline $\begin{array}{c}\text { Resin/hardener } \\
\text { ratio }\end{array}$ & \multicolumn{2}{|c|}{ Cure conditions } \\
\hline $1: 0.30$ & & \\
$1: 0.40$ & & \\
\hline $1: 0.45$ & 3 days at $25^{\circ} \mathrm{C}$ & \\
\hline $1: 0.50(\mathrm{r})$ & & \\
\hline $1: 0.55$ & & \\
\hline $1: 0.70$ & & \\
\hline
\end{tabular}

Bonded joints were fixed in the testing machine and subjected to tensile testing at the constant speed of $4 \mathrm{~mm} / \mathrm{min}$ until failure. Each attempt was monitored to register the strength characteristics of each tested joint. The observed failure was described according to ISO 10365:1992 (Adhesives - Designation of main failure patterns) [19].

\section{Results}

Mean arithmetic values of strength test results, accounting for the coefficient of variation for each test sample series, are shown in Table 2. The letter " $r$ " denotes the initial resin/hardener ratio, i.e. recommended by the manufacturer. Deviations from the initial ratio are described as a change of resin volume proportion to the recommended resin proportion, and as a real value of the applied ratio. The test results distribution in particular series is represented by the coefficient of variation, i.e. the ratio of standard deviation to the mean arithmetic values of test results in a given series.

Table 2. Mean values of elevated-temperature static strength of butt adhesive joints

\begin{tabular}{|c|c|c|c|}
\hline $\begin{array}{c}\text { Resin/hardener } \\
\text { ratio }\end{array}$ & Cure conditions & $\begin{array}{c}\text { Static joint } \\
\text { strength [MPa] }\end{array}$ & $\begin{array}{c}\text { Coefficient of } \\
\text { variation }\end{array}$ \\
\hline \multirow{2}{*}{$1: 0.3$} & 3 days at $25^{\circ} \mathrm{C}$ & 23.2 & $5 \%$ \\
\cline { 2 - 4 } & 1 hour at $100^{\circ} \mathrm{C}$ & 25.7 & $18 \%$ \\
\hline \multirow{2}{*}{$1: 0.4$} & 3 days at $25^{\circ} \mathrm{C}$ & 22.7 & $8 \%$ \\
\cline { 2 - 4 } & 1 hour at $100^{\circ} \mathrm{C}$ & 24.4 & $10 \%$ \\
\hline \multirow{2}{*}{$1: 0.45$} & 3 days at $25^{\circ} \mathrm{C}$ & 22.7 & $5 \%$ \\
\cline { 2 - 4 } & 1 hour at $100^{\circ} \mathrm{C}$ & 20.7 & $16 \%$ \\
\hline \multirow{2}{*}{$1: 0.5(\mathrm{r})$} & 3 days at $25^{\circ} \mathrm{C}$ & 20.6 & $6 \%$ \\
\cline { 2 - 4 } & 1 hour at $100^{\circ} \mathrm{C}$ & 16.7 & $12 \%$ \\
\hline \multirow{2}{*}{$1: 0.55$} & 3 days at $25^{\circ} \mathrm{C}$ & 13.9 & $9 \%$ \\
\cline { 2 - 4 } & 1 hour at $100^{\circ} \mathrm{C}$ & 10.6 & $7 \%$ \\
\hline \multirow{2}{*}{$1: 0.7$} & 3 days at $25^{\circ} \mathrm{C}$ & 6.4 & $13 \%$ \\
\cline { 2 - 4 } & 1 hour at $100^{\circ} \mathrm{C}$ & 5.2 & \multicolumn{2}{|c}{} \\
\hline
\end{tabular}




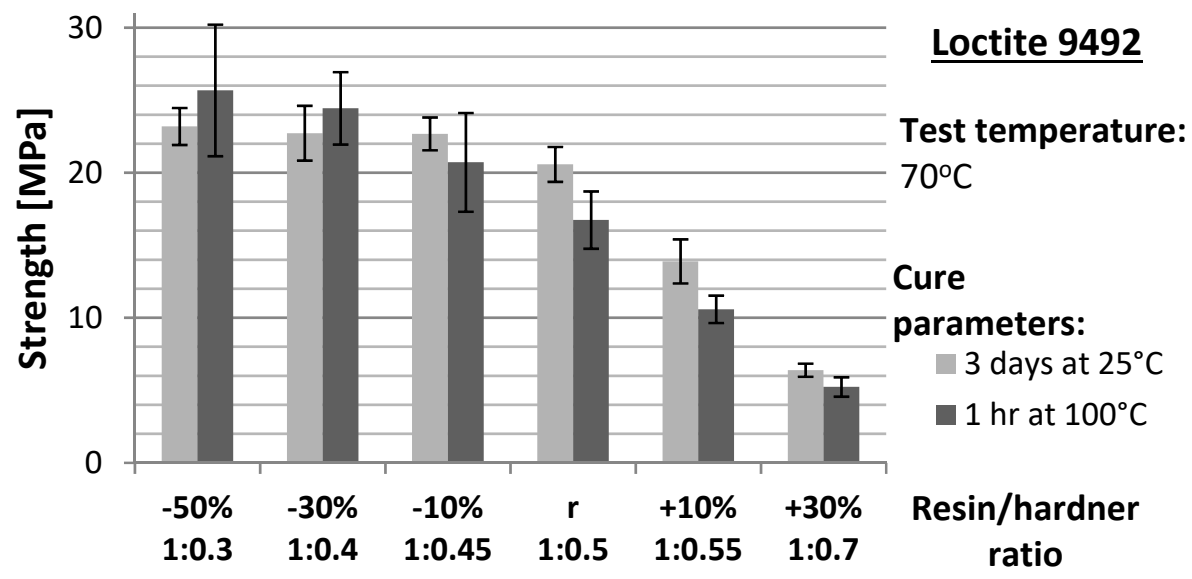

Fig. 3. Collective joint strength test results, with marked statistical analysis results (full line - equality of means, broken line - variance of means)

In order to determine whether the observed differences show statistical significance, the results were subjected to statistical analysis with the implementation of Statistica 10 software (at the standard level of significance $\alpha=0.05$ ). The analysed values that exhibited no variance, at the assumed level of significance, are connected with a full line, whereas the broken line connects values that did show the statistically relevant difference (Fig.3.).

As it has been mentioned, the observed failure was described according to the definetions detailed in the International Standard ISO 10365:1992 Adhesives - Designation of main failure patterns [19]. This organised designation has enabled evaluating the effect of such parameters as adhesive components ratio and type of cure on the character of adhesive joint failure. The surfaces of samples were visually inspected to determine the failure mode.

Table 3. Failure modes of adhesive joints bonded with Loctite 9494 at $70^{\circ} \mathrm{C}$

\begin{tabular}{|c|c|c|c|}
\hline $\begin{array}{c}\text { Resin/hardener } \\
\text { ratio }\end{array}$ & $\begin{array}{c}\begin{array}{c}\text { Cure } \\
\text { conditions }\end{array} \\
\end{array}$ & Failure mode & Fracture image \\
\hline $1: 0.3$ & & $\mathrm{CF}$ & \\
\hline $1: 0.5(\mathrm{r})$ & 3 days at $25^{\circ} \mathrm{C}$ & $\begin{array}{c}56 \% \mathrm{AF}+\mathrm{CF} \\
44 \% \mathrm{CF}\end{array}$ & \\
\hline $1: 0.7$ & & $\mathrm{AFCP}$ & \\
\hline
\end{tabular}




\begin{tabular}{|c|c|c|c|}
\hline $\begin{array}{l}\text { Resin/hardener } \\
\text { ratio }\end{array}$ & $\begin{array}{c}\begin{array}{c}\text { Cure } \\
\text { conditions }\end{array} \\
\end{array}$ & Failure mode & Fracture image \\
\hline $1: 0.3$ & & $\mathrm{CF}$ & \\
\hline $1: 0.5(\mathrm{r})$ & 1 hour at $100^{\circ} \mathrm{C}$ & $\begin{array}{c}78 \% \mathrm{AF}+\mathrm{CF} \\
22 \% \mathrm{AF}\end{array}$ & \\
\hline $1: 0.7$ & & $\mathrm{AF}$ & \\
\hline
\end{tabular}

Table 3 presents the analysis of fracture of joints cured only at room temperature and post-cured. The joint performance was tested at elevated temperature conditions.

Particular test specimens were selected according to the rule:

- minimal tested resin/hardener ratio,

- initial ratio for strength tests, described as in actual strength tests,

- maximal tested resin/hardener ratio.

The failure modes, as per the aforementioned norm, are given as: AF - adhesive failure, $\mathrm{CF}$ - cohesive failure, AC + AF - combined adhesive-cohesive failure, ACFP - adhesivecohesive failure with peeling. When the mode of failure observed in a series exhibited features of several types of failure, their percentage participation is given.

\section{Discussion}

The presented butt adhesive joint strength test results are characterised by high uniformity within particular series, which is highlighted by low values of coefficient of variation, not exceeding $15 \%$. The statistical analysis conducted in the reported study investigated whether the mean values, accounting for the scatter of results, obtained from selected test series are equal.

With regards to testing at elevated temperature, it was observed that the joint strength developed by the post-cured specimens is $19 \%$ higher than in the case of non-post-cured specimens (Fig. 4). Manipulating the resin/hardener mix ratio also proved to affect the postcured joint strength. It was shown that the increase of hardener content in the mix leads to reduced effect of post-curing on the joint strength of test samples. Simultaneously, at elevated temperature, the post-cured joints bonded with an adhesive mix of increasing hardener content (from 1:0.45 ratio onwards) exhibited an increasingly lower strength. It was therefore shown that Loctite 9492 reacts negatively to post-curing at excessive hardener content in the adhesive mix, particularly in joints that operate in high temperature conditions. From the chemical perspective, these curing conditions indicate saturation of bonds and suggest that the curing agent acts like a solvent or plasticiser. This may lead to reducing the thermal and chemical resistance of the joint. 


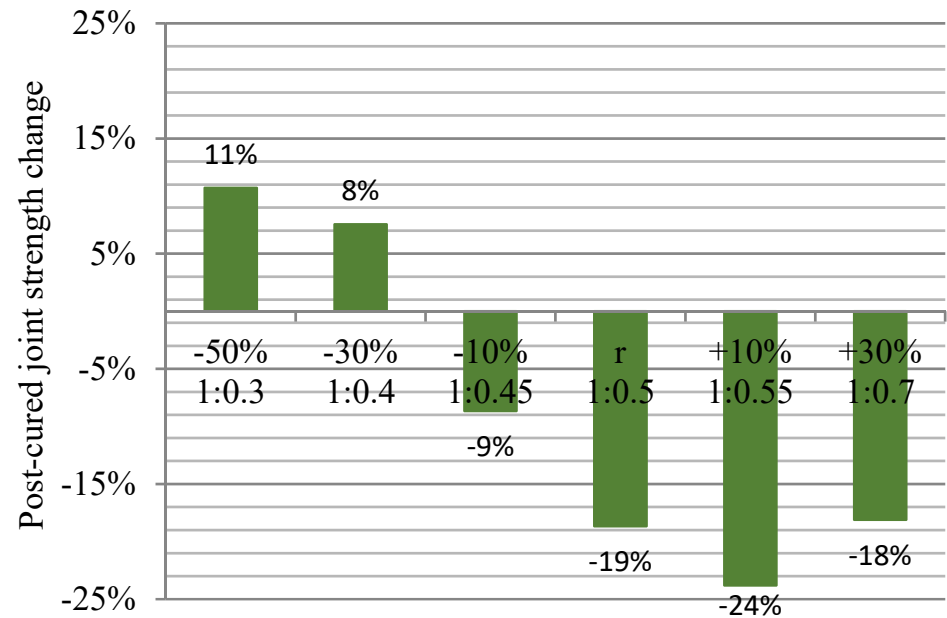

\section{Loctite 9492}

Test temperature:

$70^{\circ} \mathrm{C}$

resin<smiles></smiles>

hardner

ratio

Fig. 4. Relative change of mean static strength of butt adhesive joints between post-cured and nonpost-cured joints

The results obtained from the tests appear to indicate that subjecting the joint to thermal treatment while the epoxy adhesive is setting escalates the effect of mix ratio discrepancy on the joint strength. Fig. 5. compares relative strength of the joint with the mean strength of joint at recommended mix ratio $(r=100 \%)$ in a given series.

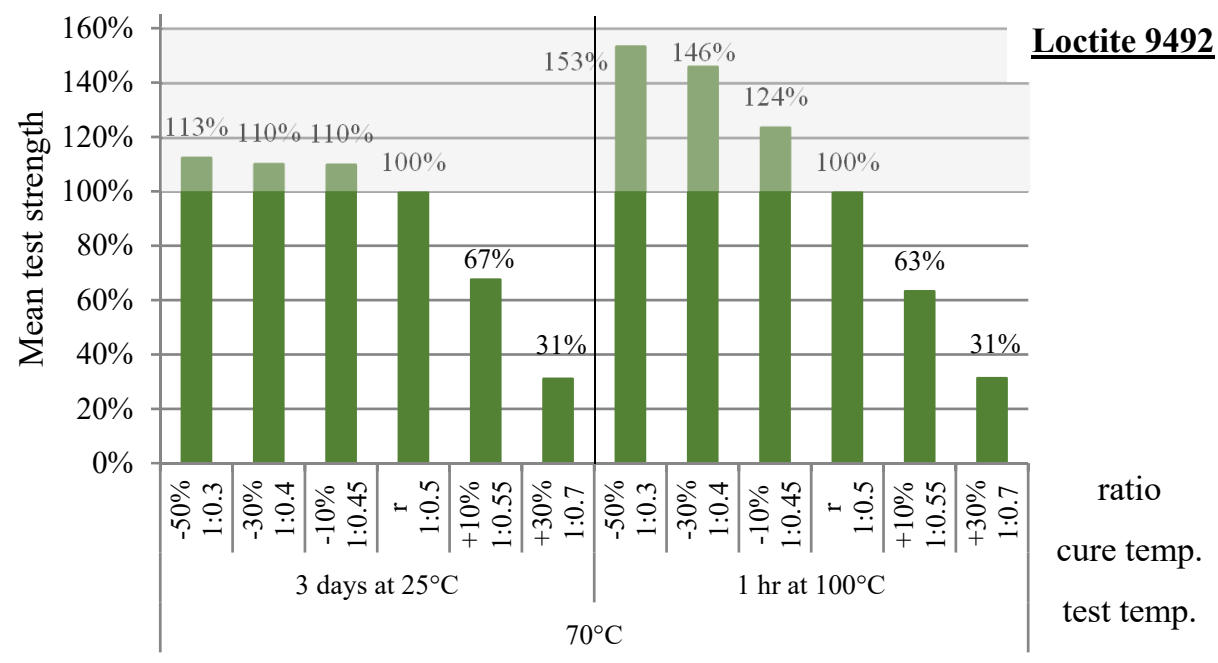

Fig. 5. Relative change of mean static strength of butt adhesive joints for the tested resin/hardener mix ratios

A part of strength parameters recorded for altered mix ratio showed in comparison negligible differences. From the data in the figure it is apparent that gradual decreasing the proportion of hardener in the mix down to $40 \%$ of the recommended amount appeared not to affect the strength of non-post-cured joints, regardless of the testing temperature. It may be, however, safely assumed that further decreasing of hardener content below $50 \%$ would result in a significant joint strength drop, nevertheless, this case was beyond the scope of this study. In the case of post-treated joints tested at elevated temperatures, it can be seen that a $30 \%$ decrease in the hardener content in the mix was translated to a marked increase in the strength 
(46-51\%: Loctite 9492) compared to the joint bonded at the recommended hardener ratio. In non-post-treated joints, however, the rise in the strength was less significant, amounting to $10 \%$. The joint strength was inhibited by $30 \%$ at $10 \%$ increased hardener ratio, and by 50 $60 \%$ when the hardener content in the adhesive mix was increased by $30 \%$ (Fig. 5).

Fig. 6. collates the comprehensive overall strength test result, i.e. the relative increase in the static strength of post-cured butt adhesive joints bonded at different hardener proportion variants related to non-post-treated joints at identical hardener proportion variants. What the figure appears to indicate is that the relative joint strength change in post-cured samples is particularly beneficial for joints bonded with reduced hardener content (compared to the initial resin/hardener ratio recommended by the manufacturer). The adhesive subjected to thermal treatment develops a strong bond even in the event of hardener deficiency. This is attributed to increased mobility of adhesive particles, which in turn boosts their reaction and chain forming capabilities.

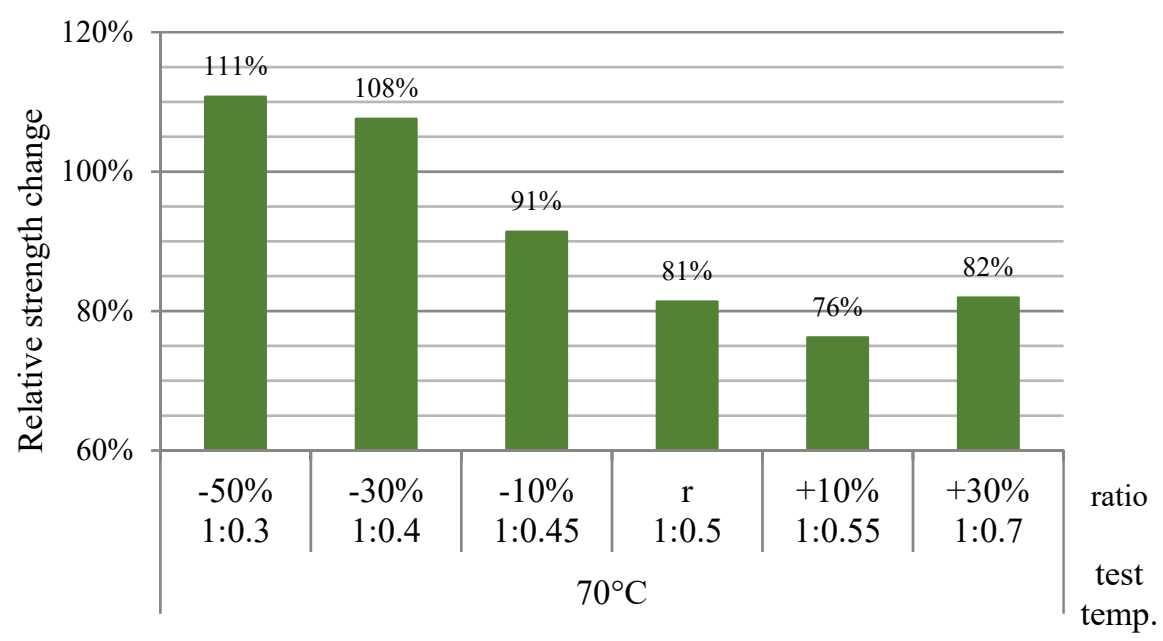

Fig. 6. Relative change of mean static strength of post-cured butt adhesive joints for the tested resin/hardener mix ratios with reference to initial ratio

The potential reason for the increased strength of post-cured joints with hardener deficiency might be the positive effect of mutual polymerisation between resin particles and increased polymerisation as a result of improved chemical functionality of epoxy resin particles, rather than the negative effect of insufficient amount of hardener. On the other hand, increasing the hardener proportion in the mix leads to a situation when the hardener begins to act like a solvent, thus reducing the level of polymerisation. Moreover, in the case of a chemical reaction between the unprocessed hardener and the adherend surface, the adhesive properties of the surface may become inhibited by surface contamination or substrate damage. In all the described defect scenarios, the strength of the assembled joint may be seriously affected.

The analysed adhesive joints exhibited different failure modes. While it was the cohesive failure that dominated in specimens bonded with the adhesive mix deficient in hardener, the gradual increase in the content of hardener translated into occurrence of the adhesive failure mode in tests. Fig. 7. shows a detailed presentation of the observed butt adhesive joint fracture modes together with their mean static strength and the dependence on the type of cure, the testing temperature, and resin/hardener mix ratio variants.

Test samples bonded with Loctite 9492 exhibited a purely cohesive failure mode when the recorded joint strength values were the highest, i.e. over $22 \mathrm{MPa}-$ which was measured 
at the recommended standard mix ratio and at reduced hardener content. The increase in the hardener proportion in the adhesive mass even by $10 \%$ led to a change in the joint failure mode: adhesive and cohesive in the substrate, although considerably high strength values were recorded. It appears to indicate that the reduced capacity of the adhesive to form bonds results from the excess of unprocessed hardener in the adhesive mass, which causes partial bonding and inconsistent bondline. Regardless of the curing method, the samples showed approximately similar adhesive-cohesive character of failure in the small range of mix ratio imbalance $( \pm 10 \%)$. The reduction in the hardener proportion in the adhesive mass positively affected the strength of bonded assemblies, and furthermore led to an increasing share of cohesive failure; in the case of a $50 \%$ deficiency in hardener in the mix the failure mode was purely cohesive.

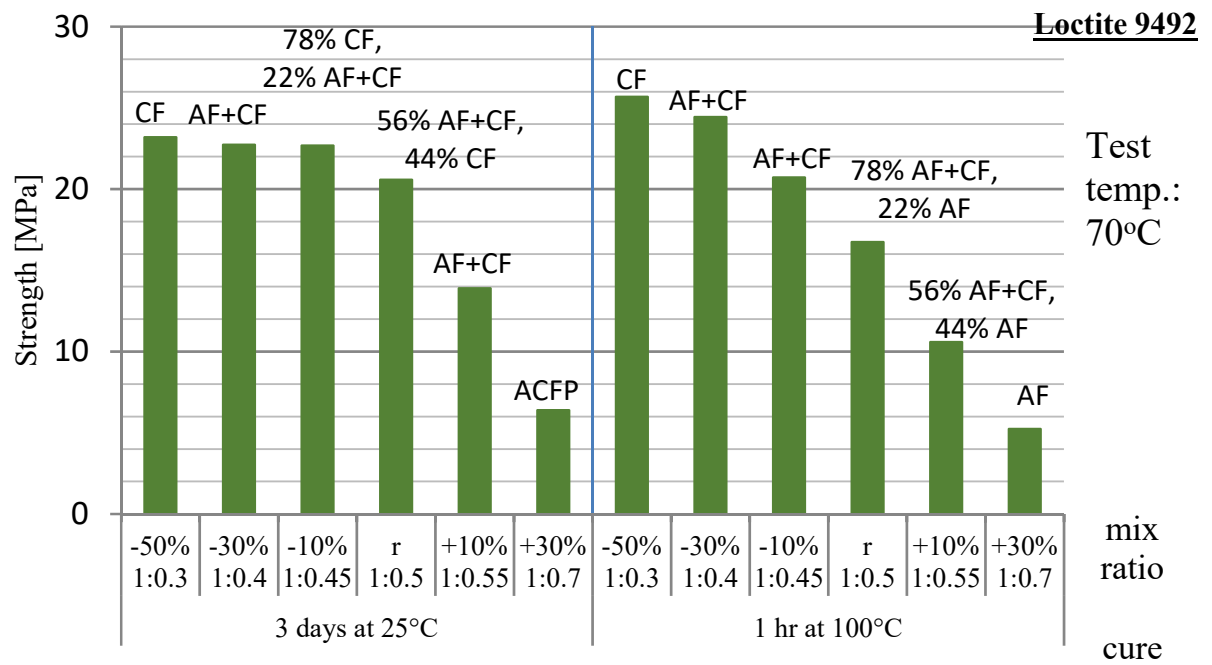

Fig. 7. Mode of joint failure versus mean static strength of butt adhesive joints depending on cure method and resin/hardener mix ratio

On the other hand, when the volume of hardener in the mix increased, the mode of failure of non-post-cured samples showed a gradual tendency towards the homogeneously adhesivecohesive, and when the hardener excess reached $30 \%$, the adhesive with peel. In the same conditions the post-cured joints showed an increasing tendency to fail adhesively. In both cases, of the post-cured and the non-post-cured joints, further increase in the hardener content diminished the strength of the assembly (Fig. 7.).

\section{Conclusions}

The results obtained from the tests lead to the conclusion that the resin/adherend mix ratio imbalance affects the strength of post-cured joints. It was found that post curing adhesive butt joints bonded with an adhesive composition with excess of hardener in the mix may thus lead to compromising the strength of joint exposed to heat during its service lifetime. The presented results shed new light on the applicability of thermal post-curing as a universal means to improve the strength properties of adhesive joints. Nevertheless, post-curing had a positive effect on the strength of bonded assemblies in the case of hardener-deficient mix ratio. The experiment detected the evidence that excessive amounts of hardener in the adhesive composition may, however, have a considerably worse effect on the final joint strength parameters. An implication of this observation may be the general recommendation for the preparation of two-component epoxy adhesives, particularly when uncertainty 
regarding the correct resin/hardener mix ratio. The negative impact of hardener excess on the adhesive properties of the bond material was observed in the change of failure mode of joint specimens with a gradual increase of the hardener proportion in the mix: the initial cohesive or adhesive-cohesive failure gradually shifted towards the adhesive failure mode. The failure mode shift was observed in the reported above technological conditions of joint formation and testing, for a particular adhesive composition. The disparity observed at elevated testing temperature regarding the change in the strength of post-cured joints, induced by the tested resin/hardener mix ratio imbalance as compared with the non-post-cured joints, indicates a higher sensitivity of thermally post-cured samples to incorrect resin/hardener mix ratio.

The obtained results are a basis for continuation of research regarding other material properties of adhesive (hardness, resilience, Young's modulus, etc.) and microstructure of adhesives with non-recommended mix ratio.

\section{References}

1. E. M. Petrie, Handbook of Adhesives \& Sealants, $1^{\text {st }}$ Edition, McGraw-Hill Professional (1999)

2. J. Godzimirski, Wytrzymałość doraźna konstrukcyjnych połaczeń klejowych, Warsaw: WNT (2002)

3. J. Kuczmaszewski, Fundamentals of metal-metal adhesive joint design, Lublin: Lublin University of Technology (2004)

4. P. Czub, Z. Bończa-Tomaszewski, P. Penczek, J. Pielichowski, Chemia i technologia zywic epoksydowych, 4th Edition., Warsaw: WNT (2002)

5. J. Bishopp, Epoxide adhesives: curatives, in Handbook of Adhesion, D. Packham, Red., Chichester, John Wiley \& Sons, Ltd, 150-155 (2005)

6. J. Pielichowski, A. Puszyński, Chemia Polimerów, Kraków: TEZA (2004)

7. M. Chanda, S. K. Roy, Industrial Polymers, Specialty Polymers, and Their Applications, CRC Press (2009)

8. A. Rudawska, M. Czarnota, Selected aspects of epoxy adhesive compositions curing process, JOURNAL OF ADHESION SCIENCE AND TECHNOLOGY, vol. 27, no. 13, 1933-1950 (2013)

9. E. O. Ozgul, M. H. Ozkul, Effects of epoxy, hardener, and diluent types on the hardened state properties of epoxy mortars, Construction and Building Materials, volume 187, 360-370 (2018)

10. G. Doyle, R. A. Pethrick, Environmental effects on the ageing of epoxy adhesive joints, International Journal of Adhesion and Adhesives, vol. 29, no. 1, 77-90 (2009)

11. J. Michels, J. S. Cruz, R. Christen, C. Czaderski, M. Motavalli, Mechanical performance of cold-curing epoxy adhesives after different mixing and curing procedures, Composites Part B, 434-443 (2016)

12. M. Muller, P. Valasek, Adhesive Bond Degradation, Engineering for Rural Development, Jelgava (2010)

13. P.-S. Shin, Z.-J. Wang, D.-J. Kwon, J.-Y. Choi, I. Sung, D.-S. Jin, S.-W. Kang, J.-C. Kim, L. K. DeVries, J.-M. Park, Optimum mixing ratio of epoxy for glass fiber reinforced composites with high thermal stability, Composites Part B: Engineering, 132-137 (2015)

14. R. F. Minty, L. Yang, J. L. Thomason, The influence of hardener-to-epoxy ratio on the interfacial strength in glass fibre reinforced epoxy composites, Composites Part A: Applied Science and Manufacturing, vol. 112, 64-70 (2018) 
15. Loctite Research, Development \& Engineering, Technical Data Sheet: EA 9492 (Hysol), (2014)

16. J. Szabelski, J. Domińczuk, Analiza Wpływu Obróbki Termicznej Na Wytrzymałość Połaczeń Gwintowo-Klejowych, Innowacje w Zarządzaniu i Inżynierii Produkcji, vol. 1, R. Knosala, Opole, 805-814 (2014)

17. Standard PN-EN 15870:2009E - Adhesives. Determination of tensile strength of butt joints

18. Standard PN-EN 13887:2005P - Structural adhesives. Guidelines for surface preparation of metals and plastics prior to adhesive bonding.

19. Standard PN-EN ISO 10365:1998P - Adhesives - Designation of main failure patterns. 